\title{
Evaluation of chronic alcohol self-administration by a 3-bottle choice paradigm in adult male rats. Effects on behavioural reactivity, spatial learning and reference memory
}

\author{
Silvana Cacace ${ }^{1}$, Fulvio Plescia ${ }^{1}$, Marco La Barbera, Carla Cannizzaro* \\ Department of Pharmacological Sciences “P. Benigno”, University of Palermo, V. Vespro 129, 90127 Palermo, Italy
}

\section{A R T I C L E I N F O}

\section{Article history:}

Received 7 July 2010

Received in revised form

30 December 2010

Accepted 10 January 2011

Available online 14 January 2011

\section{Keywords:}

Alcohol self-administration

Free-choice paradigm

Alcoholic preference

Explorative behaviour

Spatial learning

Reference memory

\begin{abstract}
A B S T R A C T
Chronic ethanol consumption is able to modify emotional behaviour and cognition in humans. In particular, the effects exerted by alcohol may depend on doses, time and modalities of administration. In this study we investigated, in adult male rats, ethanol self-administration and preference patterns using a 3-bottle choice paradigm with water, $10 \%$ ethanol solution, and white wine (10\%,v/v), along a fourweek period. The influence of alcohol free-access on novelty-induced explorative behaviour in the open field, and on spatial learning and reference memory in the Morris water maze was also evaluated. Our results indicate that: (i) rats show a higher preference for alcohol, in the first two weeks of the paradigm, displaying a higher consumption of $10 \%$ ethanol solution than white wine; in the last two weeks, they reduce their alcoholic preference, drinking the same moderate amounts of the two alcoholic beverages; (ii) at the fourth week of the free-access paradigm rats show a high explorative behaviour in the central squares of the open field and an improvement in spatial information processing in the new-place learning task of the Morris water maze. In conclusion our data suggest that, interestingly, rats exposed to the free-access paradigm were able to self-regulate their alcoholic intake, and indicated that a moderate alcohol consumption was able to induce an increase in behavioural reactivity and an enhancement in spatial learning flexibility.
\end{abstract}

(C) 2011 Elsevier B.V. All rights reserved.

\section{Introduction}

Among the several aspects and characteristics of ethanol, taste takes on particular importance in humans. The different alcoholic beverages vary, besides in alcoholic content, also in taste and flavours, and for some individuals they seem to be anecdotally important in their choice of an alcoholic brand. Thus, taste represents the main boost during alcohol approaching, whereas drinking behaviour is more correlated to the metabolic and central effects of ethanol [1-3]; subsequently, and in particular during alcohol abuse, rewarding effects play a priority role together with negative reinforcement $[4,5]$. Alcoholic drinks, such as wine, are produced by alcoholic fermentation of fruit simple carbohydrates; sugar fermentation by yeasts occurs in nature so that some ripe wild fruits contain traces of ethanol up to $0.6 \%$ [6]. Fruit-eating animals must then inevitably consume alcohol on a regular basis, as a part of the normal behavioural repertoire: this makes rodents an ideal subject

\footnotetext{
* Corresponding author. Tel.: +39 091 6553215/60; fax: +39 0916553260 .

E-mail addresses: carla.cannizzaro@katamail.com, carlacannizzaro@unipa.it (C. Cannizzaro).

1 These authors contributed equally to this work.
}

for studying alcohol-drinking behaviour [7-9]. One commonly used approach for modelling human alcohol consumption in rodents is the alcohol preference study, in which animals are given a choice between water and alcohol solutions of various strength, and the amount of each fluid consumed is measured. Usually, at the beginning, rats prefer low-dose alcohol solutions $(<6 \%)$, because of their "sweet taste" [8], then high-dose ones [10]. Animal models of drug self-administration are important in determining the behavioural effects of alcohol, as well as of other drugs of abuse, as they provide controlled environments in which the subject self-administers the compound. Furthermore, experimental studies of acquisition of drug self-administration in drug-naive animals are important to investigate factors that affect vulnerability to initiation of drugabuse in humans. Given these preliminary remarks, the first goal of the present study was to examine ethanol intake and preference patterns in heterogeneous adult male Wistar rats, using a 3-bottle choice paradigm with water, $10 \%$ ethanol solution, and white wine $(10 \%, v / v)$, along a four-week period, in order to assess whether the organolectic properties of white wine could play a role in the initiation and maintenance of alcohol voluntary drinking in rats.

It is widely reported that chronic ethanol consumption is able to modify emotional behaviour and cognition in humans: approximately $75 \%$ of alcoholic patients will show some cognitive deficits 


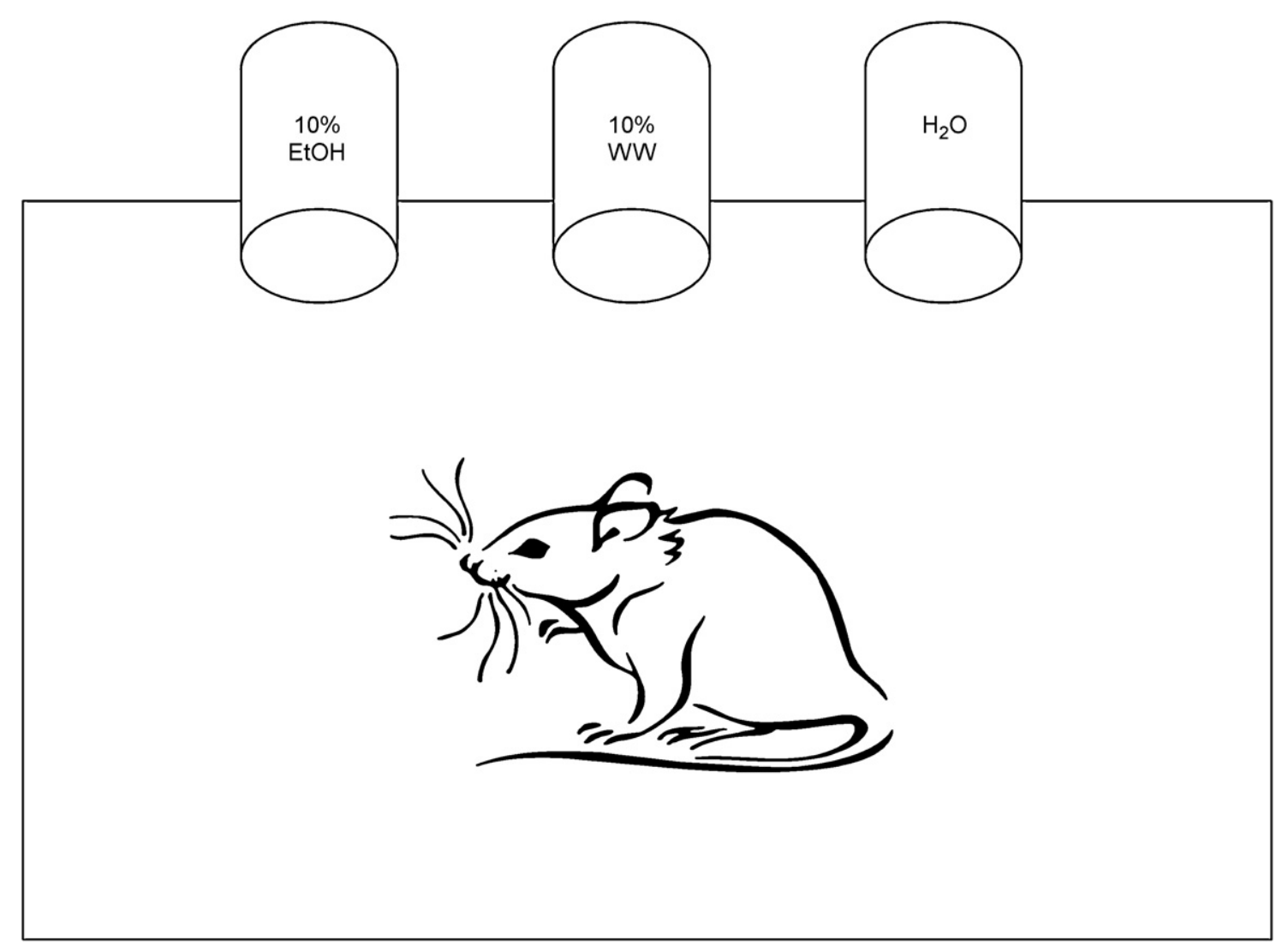

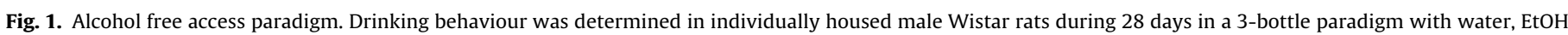
$10 \%$, and white wine.

[11], such as impairments in intellectual function, memory, verbal and non verbal learning, visual-motor coordination, cognitive flexibility, executive functions, problem solving, decision-making, perception, information processing speed [12-16]. On the other hand recent reports suggest that moderate alcohol consumption may induce discrete beneficial health effects including lower risk for total and ischemic stroke [17], coronary heart disease [18-20], and dementia later in life [21], as well as a potentiation of visual and emotional memory traces [22,23]. Similarly, several reports on animal studies show a plethora of effects exerted by ethanol on different behavioural patterns, which depend on doses, time and modalities of administration. As a matter of fact, ethanol can have both stimulant and depressive behavioural effects [24,25]. In rodents the stimulant action of low doses of ethanol has generally been assessed using locomotor behaviour, [26,27]. Further studies show that anxiety-related behaviours are positively correlated with ethanol consumption [28-31], while other reports do not show this relationship $[32,33]$. Thus, in order to contribute to a further clarification on this argument, and taking advantage of the three-bottle choice paradigm, the second aim of this study was to investigate the possible influence of alcohol self-administration on novelty-induced explorative behaviour, assessed in an open field, as a measure of the emotional state of the animals [34].

It is widely described that high-dose ethanol exposure exerts detrimental effects on rat cognitive processes such as learning and memory [35-38]. However, some other reports show that chronic exposure to an ethanol containing diet can induce a better performance in discrete cognitive tasks depending on dosage and time of consumption $[39,40]$. Since alcohol does not affect all memory processes, in the same way it is useful to analyze the effects of chronic

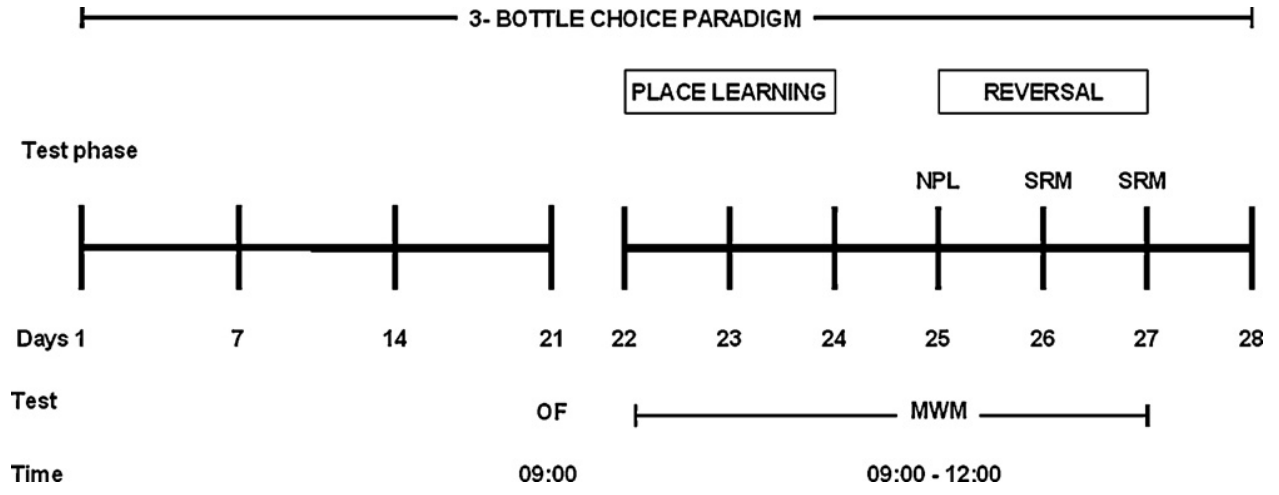

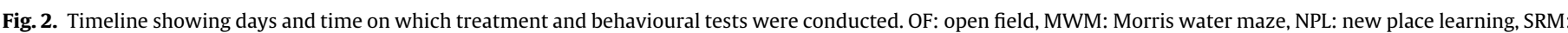
spatial reference memory 


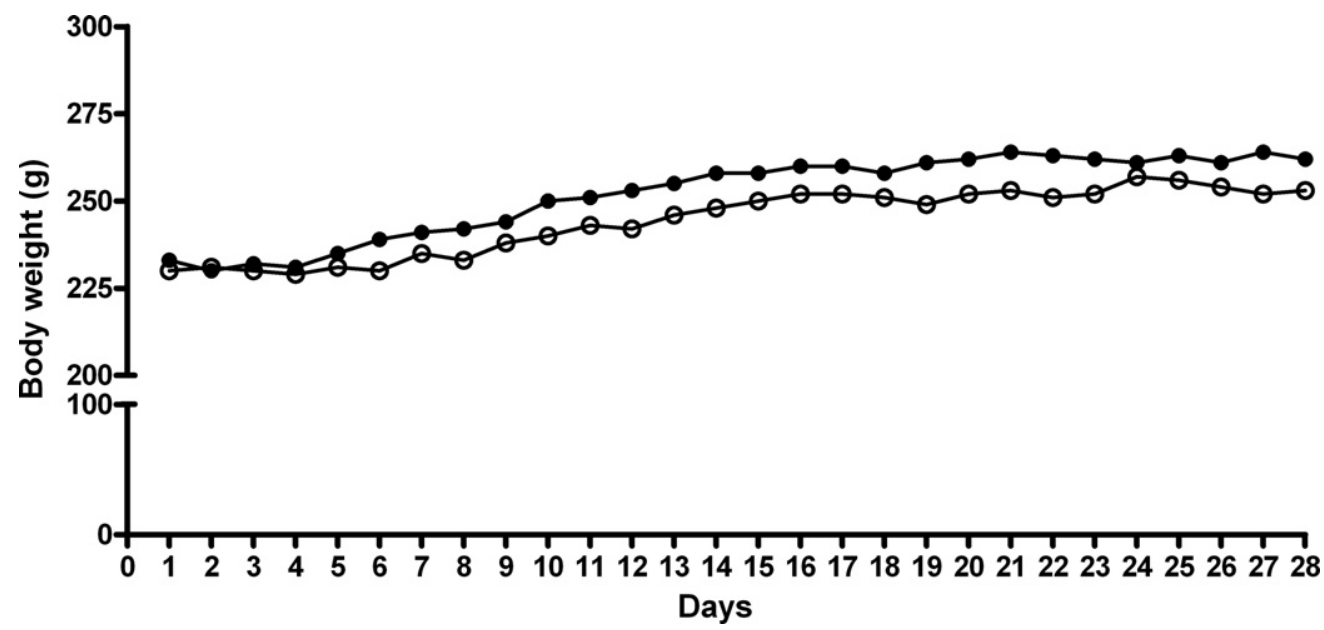

Fig. 3. The mean of body weight ( $\mathrm{g}$ ) along the 28 days of 3-bottle choice paradigm. Each value represents the mean \pm S.D. of twelve rats per day. (

CTR, (O) AFA.

alcohol consumption on distinct memory tasks. For this aim, the effects of alcohol self-administration have been finally evaluated using the Morris water maze. Here, spatial navigation was measured during an acquisition training, which explores learning and long-term retention of spatial information, and a reversal phase in which flexibility in spatial strategies and reference memory are requested. Rats were tested during the fourth week of alcohol freeaccess paradigm, so that no possible withdrawal symptoms could interfere with their performance in the cognitive tasks.

\section{Materials and methods}

\subsection{Animals and housing conditions}

Twenty-four adult male Wistar rats bred in our laboratory were used in the experiments (originally obtained from Harlan, Udine, Italy) weighing respectively, $200-250 \mathrm{~g}$, and maintained on a $12 \mathrm{~h}$ on/off cycle $(8: 00-20: 00 \mathrm{~h})$ in a temperaturecontrolled room $\left(22 \pm 2^{\circ} \mathrm{C}\right)$. The animals were randomly assigned to one of the two following groups: alcohol free-access (AFA, $n=12$ ) - and control group (CTR, $n=12$ ). AFA-rats were given free access to food, water, white wine and ethanol solution. All control rats were given free access to food and water. Rat body weight and food intake were daily recorded. On the test days, the animals were brought into the laboratory and allowed to acclimatise for at least $60 \mathrm{~min}$ prior to the experimental session. The experiments were performed in a sound isolated chamber between 9:00 $\mathrm{h}$ and 14:00 h. Animal performance was recorded on a videotape monitored in an adjacent room. An experimenter, unaware of the different treatments, scored the parameters from the videotape. The devices were thoroughly cleaned with ethanol solution $10 \%$, than dried with tissue paper, and rinsed again with water. This procedure was conducted 10 min before animals' entry into the cages, to ensure that the particular rat's behaviour was not affected by the detection of another rat's scent. To exclude effects of ethanol withdrawal, behavioural testing was conducted in the

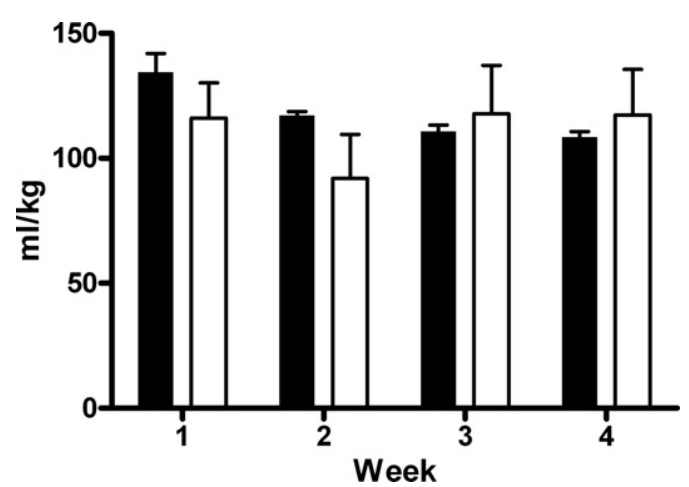

Fig. 4. The mean of water intake $(\mathrm{ml} / \mathrm{kg})$, during the four weeks of the free access paradigm. Each value represents the mean \pm S.D. of twelve rats per day. ( $(\mathbf{\square})$ CTR, ( $\square$ ) AFA. first $2 \mathrm{~h}$ of the light cycle, when rats were still active and feeding. All the experiments were in accordance with the regulations of the committee for use of experimental animals of the University of Palermo.

\subsection{Alcohol free-access paradigm}

AFA-rats had daily free access to ethanol $10 \%(\mathrm{v} / \mathrm{v})$, white wine (Tavernello 11 vol.\%, Italy, diluted with water to final 10 vol.\%) and water (Fig. 1) along the four weeks of the paradigm (Fig. 2). All the solutions were daily prepared and, before their replacement, the volumes consumed were recorded. The unrestricted and

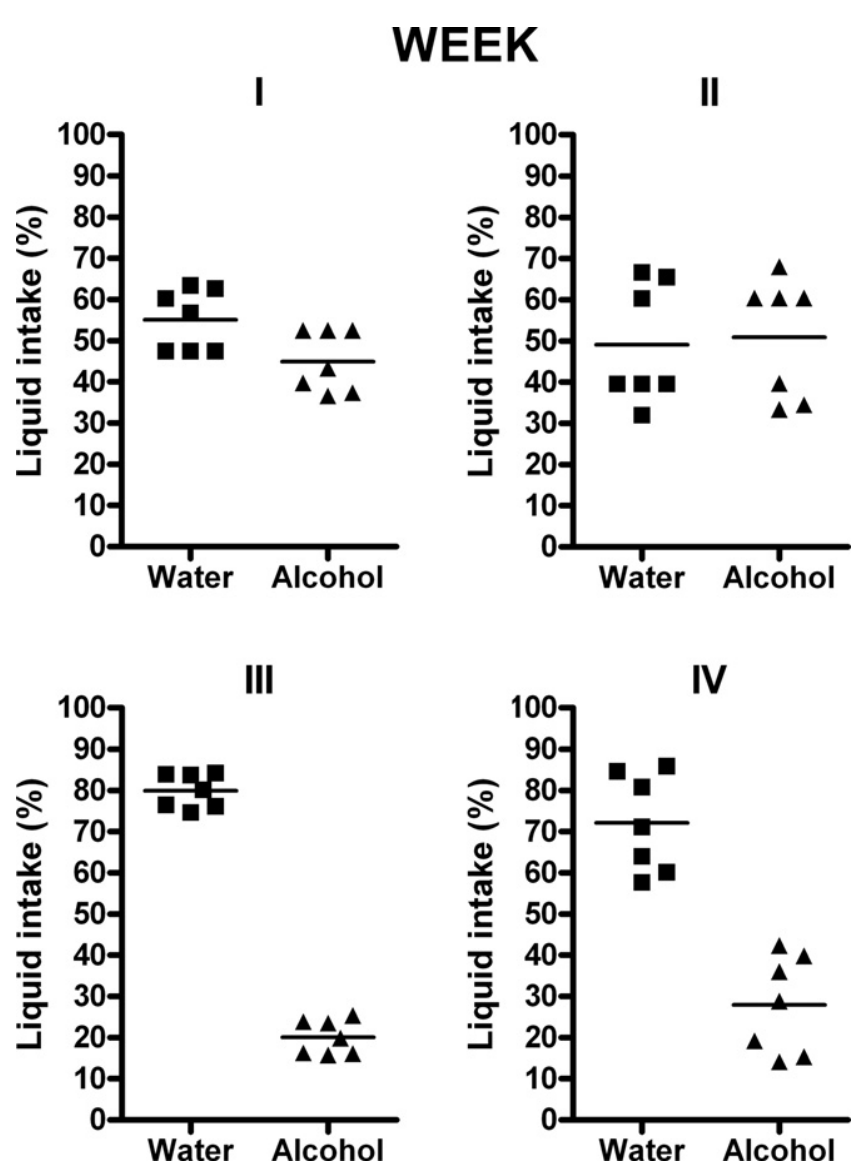

Fig. 5. Alcohol vs. water preference on each week of the 3-bottle choice paradigm, expressed as percentage of alcohol or water $(\mathrm{ml}) /$ total fluid intake $(\mathrm{ml})$. Each value represents the mean \pm S.D. of twelve rats per day. 


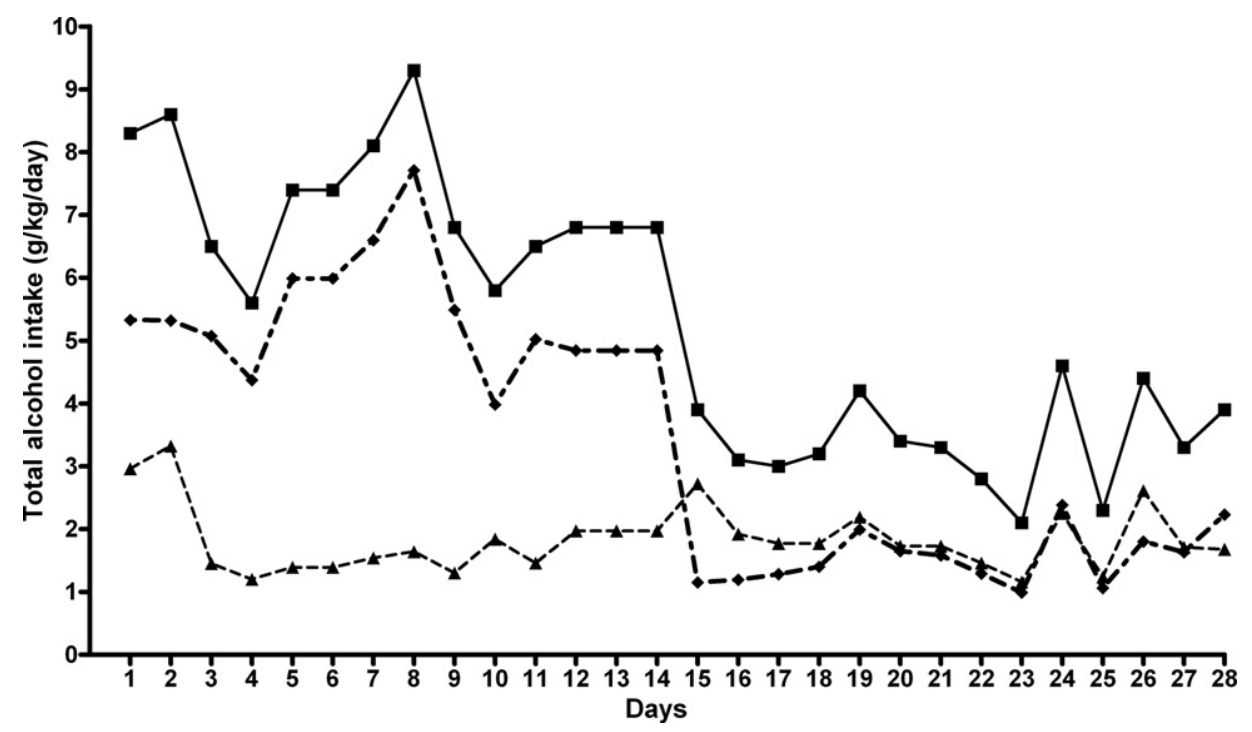

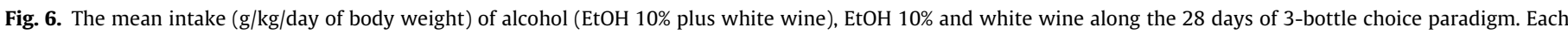
value represents the mean \pm S.D. of twelve rats. ( $)$ EtOH; $(\Delta)$ white wine and ( $\mathbf{\square})$ EtOH plus white wine.

continuous access to the ethanol containing solution ruled out the chance that alcohol withdrawal could be a factor [40]. When authors report "alcohol preference or intake", they mean ethanol $10 \%$ plus white wine intake. The control group had free access to water.

\subsection{Open field test}

Locomotor activity and explorative behaviour were measured in an open field (OF) with a contrast-sensitive, video tracking system, the Opto-Varimex (Columbus Instruments, USA). This apparatus was a square box, $44 \mathrm{~cm}$ wide, $44 \mathrm{~cm}$ long and $20 \mathrm{~cm}$ high, whose perpendicular sides have 15 infrared emitters. Each beam was separated from the next one by a distance of $2.54 \mathrm{~cm}$. The apparatus produces a qualitative mapping of the motor patterns, measuring different parameters simultaneously: total distance travelled (TDT) as a measure of locomotor acitivity; number of transitions (NTC) from peripheral to central squares of the arena, and amount of time spent on the central areas (ATC) as measures of explorative behaviour. The animal behaviour was recorded $1 \mathrm{~min}$ after the rats were placed in the box, during 5 min and displayed on a PC.

\subsection{Morris water maze}

The Morris water maze (MWM) apparatus used in these experiments is a circular, light-blue swimming pool with the following dimensions: diameter $160 \mathrm{~cm}$; walls, $70 \mathrm{~cm}$ high. It was filled with normal tap water to a depth of $50 \mathrm{~cm}$. The water temperature was carefully maintained at $23 \pm 2{ }^{\circ} \mathrm{C}$. The pool was divided in four quadrants of equal size by two imaginary diagonal lines running through the centre, designated NW, NE, SW and SE. A removable square escape platform $(10 \mathrm{~cm} \times 10 \mathrm{~cm})$ could be positioned in the middle of the quadrants, with the centre $30 \mathrm{~cm}$ away from the wall and $1.5 \mathrm{~cm}$ below the water level, in order to be invisible to the swimming rat. The pool was placed in an experimental room provided with several extra-maze cues (e.g. bookshelves and posters), and remained immobile in the room throughout the entire experimental period. The swimming pool was illuminated by a white light $(60 \mathrm{~W})$. An automatic video system (ANY MAZE Video Tracking System, Ugo Basile, Italy) was used to record the animal movements in the pool. The paths taken by the animals in the pool were monitored by a video camera mounted in the ceiling. This program provided us measures of latency, path length, swim speed, the distribution of time spent in defined regions of the pool.

\subsection{Morris water maze experimental design}

The MWM protocol used in this study (modified from [41]) was chosen in order to assess learning, reference memory and spatial flexibility along the following experimental sessions:

\subsubsection{Place learning with multiple trials (days 1-3)}

Place learning consisted in training the rats to escape from the water reaching a hidden platform placed in SE zone, where it was maintained throughout the experimental session. Rats were put into the pool facing the walls of each quadrant, in the following order of starting points: NE, SW, NW, SE. Each animal underwent four daily trials over a period of three days, and they were allowed to swim until the escape on the platform (escape latency), for a maximum of $90 \mathrm{~s}$. When they found the platform, they were left for $15 \mathrm{~s}$ on it. If the rats did not find the escape platform within $90 \mathrm{~s}$, the experimenter guided them gently to the platform where they were allowed to remain for $15 \mathrm{~s}$ to reinforce the information on the visuospatial cues in the environment. During the 5 min inter-trial intervals, the animals were replaced into their home cages and briefly warmed under a heating lamp. The parameters recorded were: escape latency $(\mathrm{s})$, path length $(\mathrm{m})$, and swimming speed $(\mathrm{m} / \mathrm{s})$ as mean values along the four trials of each day of the experiment.

\subsubsection{Reversal (days 4-6)}

The reversal phase consisted of two different assessments, which investigated the following behavioural skills:
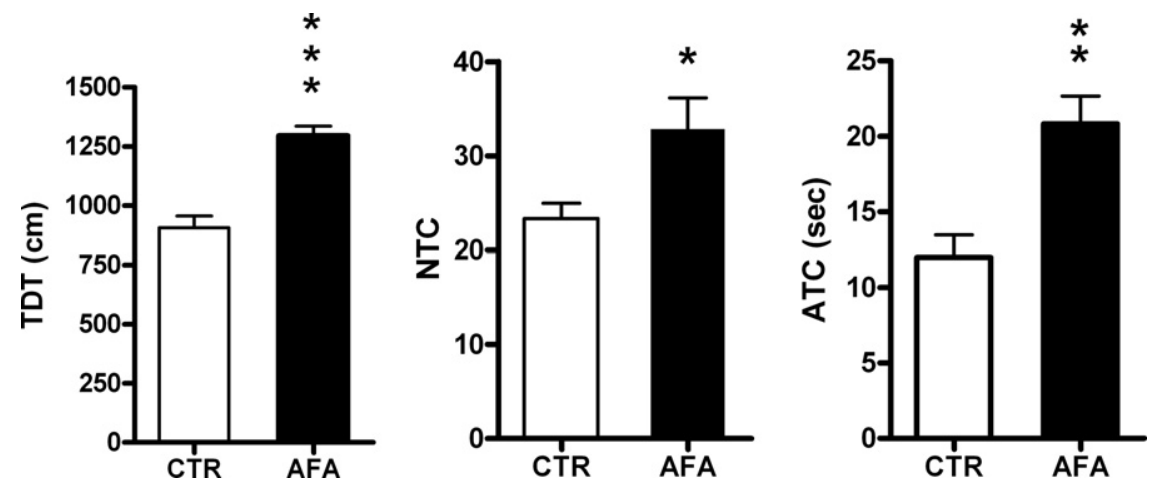

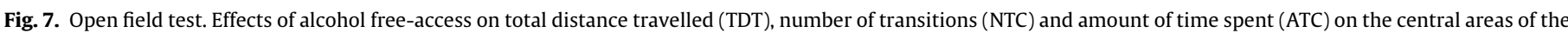
arena. Each value represents the mean \pm S.D. of twelve rats. ${ }^{* * *} p<0.001 ;{ }^{* *} p<0.01 ;{ }^{*} p<0.05$ vs. CTR rats. 


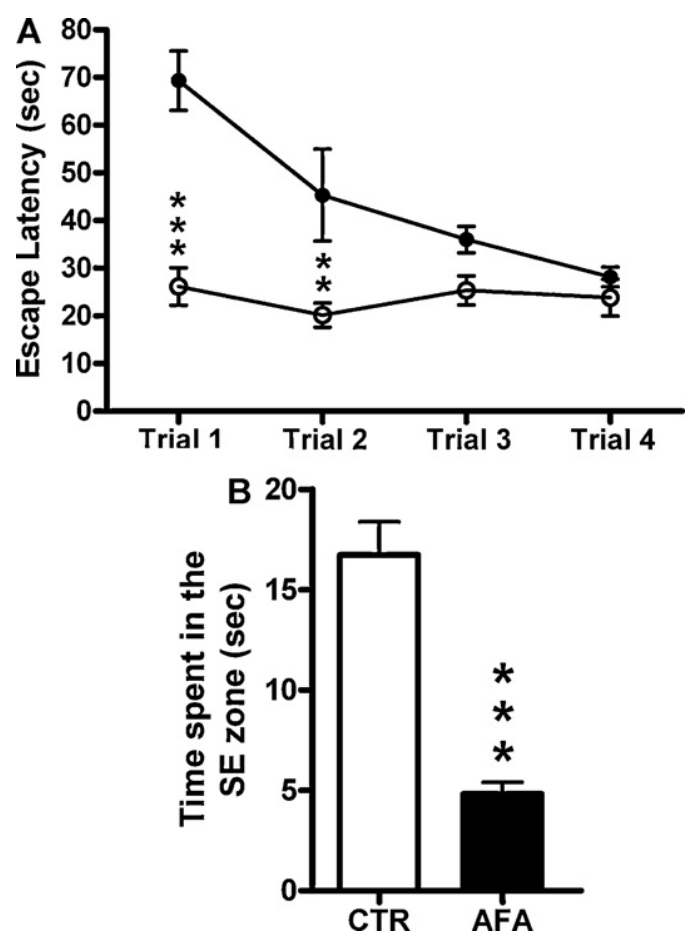

Fig. 8. MWM: new place learning task. Effects of alcohol-free access on: escape latency (A) along the four trials of the first reversal day; on time spent on SE quadrant (B) during the first trial of the first reversal day. Each value represents the mean \pm S.D. of twelve rats. (๑) CTR, (○) AFA. ${ }^{* * *} p<0.001 ;{ }^{* *} p<0.01$ vs. CTR rats.

2.5.2.1. New place learning (day 4). On the first day of the reversal experiment, the position of the escape platform was moved to the opposite quadrant (NW) with respect to the place learning session. In this task, the rats were required to learn the new location of the platform along 4 trials. Starting points, trial duration, intertrial interval and reinforcement time spent onto the platform were same as in the initial place learning. Latency time was measured as in the initial place learning, in addition to the time spent on the former location of the platform (SE quadrant), in order to evaluate the degree of the previous mnemonic persistence. Path length and speed were also recorded in order to obtain additional elements in search strategies.

2.5.2.2. Spatial reference memory (day 5-6). On the second and third day of the reversal task, the position of the platform was maintained in the same quadrant as in the initial new place learning, for four trials per day. The escape latency was recorded as a measure of acquisition and retrieval of the spatial information necessary to reach the platform location. Path length and swimming speed were also recorded. Starting points, trial duration, inter-trial interval, reinforcement time on the platform, and any other experimental conditions were same as in the previous day.

\subsection{Data analysis}

Alcohol free-access paradigm: differences in the preference between ethanol $10 \%$ and white wine, were assessed by a two-way ANOVA, with "conditions" as a between-subjects factor and "days" as repeated measurement factor.

Open field test: evaluation of locomotor activity and explorative behaviour were conducted performing a two-tailed Student's t-test for unpaired measures on total distance travelled, number of transitions from peripheral to central squares, and amount of time spent on the central quadrants of the arena in order to assess "AFA" effects on behavioural reactivity.

Morris water maze: a two-way ANOVA was conducted on escape latency, path length, swimming speed, and time spent on SE quadrant (on day 4), taken as dependent variables, with "alcohol free-access" (treatment) as a betweensubjects factor, and "days" or "trials" as repeated measurement factor. When necessary, simple main effects and post-hoc comparisons were calculated with Bonferroni post test $(\alpha=0.05)$. Differences were considered statistically significant if $p<0.05$

\section{Results}

\subsection{Body weight, food intake and consumption of ethanol, wine} and water

AFA- and control rats were screened for body weight and food pellet intake, along the entire three-bottle choice paradigm using a two-way ANOVA. Our results show that no differences between AFA- and CTR animals were observed in mean body weight, (251 $\pm 11.89 \mathrm{~g} ; 244 \pm 9.5 \mathrm{~g}$ ) (Fig. 3), in mean water intake $(117.16 \pm 14.7 \mathrm{ml} / \mathrm{kg} ; 110.78 \pm 44.9 \mathrm{ml} / \mathrm{kg}$ ) (Fig. 4) as well as in mean food intake $(26.21 \pm 5.78 \mathrm{~g} ; 24.9 \pm 3.19 \mathrm{~g})$ during the four weeks of the experiment. AFA-rats showed a different alcohol preference, with respect to total liquid intake, along the four weeks of measurement: during the first two weeks, mean alcohol preference was $47.5 \%$ while in the last weeks their preference decreased to $24 \%$ (Fig. 5). These results were paralleled by data from daily intake of ethanol plus white wine, expressed as $g$ of alcohol per $\mathrm{kg}$ of body weight, showing that rats consumed higher concentrations of alcohol during the first $(7.4 \pm 1.1 \mathrm{~g} / \mathrm{kg})$ and the second week $(7.0 \pm 1.1 \mathrm{~g} / \mathrm{kg})$, while a drastic reduction was observed in the last two weeks $(3.4 \pm 0.4 \mathrm{~g} / \mathrm{kg} ; 3.3 \pm 0.9 \mathrm{~g} / \mathrm{kg}$ ). When the daily intake of ethanol and white wine, expressed as $\mathrm{g}$ of alcohol per $\mathrm{kg}$ of body weight, was analyzed separately, it was shown that rats consumed larger amounts of ethanol solution than white wine, in the first and the second week of the free-access paradigm, while in the third and fourth week rats reduced their ethanol intake to the same values of white wine (Fig. 6).

Indeed, a two-way ANOVA for repeated measures performed on AFA-rats' preference for wine or ethanol solution, per week, along the free-choice paradigm, revealed significant effects of drink choice $\left(F_{(1,11)}=721.470, p<0.001\right)$, time $\left(F_{(3,33)}=54.409, p<0.001\right)$ and their interaction $\left(F_{(3,33)}=283.569, p<0.0001\right)$. A post-hoc analysis revealed a higher preference for ethanol $(t=28.180, p<0.001)$ $(t=27.753, p<0.001)$ with respect to white wine during the first and the second week. AFA-rats ingested constant volumes of white wine along the free-access paradigm, showing a low preference for this beverage, with respect to ethanol solution.

\subsection{Open field test}

When the animals were tested in the open field arena at the end of the third week of AFA, in order to evaluate behavioural reactivity in response to novelty, a different behavioural pattern was observed in the two experimental groups (Fig. 7). Both locomotor activity and explorative behaviour were affected by AFA-procedure: in particular statistical analysis by a two-tailed Student's $t$-test, showed a significant increase in total distance travelled $[(t=6.121, \mathrm{df}=22 ; p<0.0001)]$, number of transitions $[t=(2.572), \mathrm{df}=22 ; p<0.0174]$ and amount of time spent on the centre of the arena $[t=(3.778), \mathrm{df}=22 ; p<0.001]$ in AFA-rats when compared to controls.

\subsection{Morris water maze}

\subsubsection{Place learning with multiple trials (days 1-3)}

Statistical analysis of escape latencies, swimming speed and path length to reach the hidden platform revealed that AFA paradigm did not affect place learning in the MWM since no significant differences were observed between the groups: AFA- and control rats improved their performance over days as supported by the significant main effect of days for latency $\left[\left(F_{(2,188)}=67.45\right.\right.$, $p<0.0001)]$, path length $\left[\left(F_{(2,188)}=56.32, p<0,0001\right)\right]$ and swimming speed $\left[\left(F_{(2,188)}=11.91, p<0.0001\right)\right]$. A post-hoc analysis revealed that AFA- and control rats displayed a significant reduction on training day 2 and 3 , with respect to the previous training 
days in: escape latency $[(t=5.858, p<0.001 ; t=5.535, p<0.001)$, $(t=2.288, p<0.05 ; t=2.263, p<0.05)]$ and path length $[(t=4.695$, $p<0.001 ; t=5.337, p<0.001),(t=2.286, p<0.05 ; t=2.366, p<0.05)]$. A reduction in swimming speed in training day $2(t=2.646, p<0.05$; $t=2.924, p<0.01)]$ was recorded in both groups, compared to the previous training day.

\subsubsection{Reversal (days 4-6)}

Data from each parameter of the reversal experiment were analyzed using a two-way ANOVA for repeated measures including "treatment" as the between-subjects factor and "days" as within subjects factor, followed by a Bonferroni post test. AFA-rats displayed a different performance in this task with respect to controls, on the first day of the reversal (day 4): indeed, the escape latency and the path length to reach the platform in the new location were significantly reduced, with respect to controls. This was supported by a significant interaction between "treatment" and "days" $\left(F_{(2,188)}=15.23, p<0.0001 ; F_{(2,188)}=9.97, p<0.0001\right)$ and by a posthoc analysis that revealed a significant main effect of treatment on day $4(t=4.671, p<0.001 ; t=3.073, p<0.01)$. There were no significant differences in swimming speed.

Values from each trial per day were analyzed in order to get detailed information on the different behavioural strategies performed by the two experimental groups to achieve the different memory tasks required, the new place learning and the reference memory task.

3.3.2.1. New place learning task (day 4). A two-way ANOVA for repeated measures including "AFA treatment" as the betweensubjects factor and "trial" as within subjects factor on escape latency and path length showed a significant effect for "treatment" $\left(F_{(1,22)}=10.69, p<0.0035 ; F_{(1,22)}=4.67, p<0.0418\right)$, for "trial" $\left(F_{(3,66)}=14.26, p<0.0001 ; F_{(3,66)}=6.04, p<0.0011\right)$ and for their interaction $\left(F_{(3,66)}=14.70, p<0.0001 ; F_{(3,66)}=3.05, p<0.0347\right)$. A post-hoc analysis revealed that AFA-rats displayed a significant lower escape latency to reach the new platform location than controls in the first and in the second trial $(t=5.993, p<0.001$; $t=3.147, p<0.01$ ) (Fig. 8A), as well as a shorter path length on the first trial $(t=2.989, p<0.05)$. Records from time spent on SE quadrant analyzed by a Student's $t$-test showed a higher preference for the former location of the platform in controls on the first trial $[(t=(6.852), \mathrm{df}=22, p<0.0001)$ (Fig. 8B). The discrepancy in escape latency and path length between the two groups attenuated in the third trial and disappeared in the fourth trial. No differences were observed in swimming speed along the trials.

3.3.2.2. Spatial reference memory task (day 5 and 6). Although AFArats tended to display a better performance for swimming speed and path length in the second and third trial on day 5 , there were no significant differences between the two groups in all the parameters examined. Both of them improved their performance along the trials as supported by the significant main effect of "trial" for latency and "path length" on day $5\left(F_{(3,66)}=8.52, p<0.0001 ; F_{(3,66)}=14.91\right.$, $p<0.0001)$ and on day $6\left(F_{(3,66)}=22.94, p<0.0001 ; F_{(3,66)}=8.30\right.$, $p<0.0001)$, showing that animals from both groups reached the same general level of performance.

\section{Discussion}

In this study we used a free-choice paradigm including water, a $10 \%$ ethanol solution, and white wine $(10 \%, \mathrm{v} / \mathrm{v}$ ethanol) in order to investigate in adult male rats alcohol preference with respect to total fluid intake, the overall amount of alcohol consumed, and the preference between the two different alcoholic beverages, along a 28-day period. The effects exerted by alcohol ingestion on behavioural reactivity and cognitive behaviour were then evaluated during the fourth week of the alcohol free-access paradigm, employing respectively the open field test and the Morris water maze.

It is important to underline that this experimental design was not aimed to the setting up of an animal model of alcohol dependence or withdrawal, but it addressed other issues, i.e. the initial alcohol acceptance and maintenance of intake when an alcoholic beverage with different organoletic properties, i.e. white wine, was available.

Our results show that during the 4-week 3-bottle choice paradigm, adult male Wistar rats displayed a higher alcohol intake in the first and in the second week of the paradigm, reaching a $47 \%$ preference with respect to total fluid intake; in the last two weeks AFA-rats' alcoholic preference decreased and set up to a final $24 \%$. [7,8]. Indeed, rat drinking behaviour showed an irregular trend: during the first days of alcohol exposure, male rats displayed dramatic peaks in alcohol consumption, consistently with some other reports $[42,43]$. Following this short initiation phase, large daily fluctuations in drinking behaviour were observed and, after the first two weeks, alcohol consumption decreased to values (3-4 g/ kg/day) generally considered as moderate [44]. This irregular pattern might resemble the initial binge-like drinking behaviour observed in humans; it was then ensued by a voluntary reduction in alcohol intake. This result is difficult to explain on the basis of our behavioural observations; nevertheless, we can hypothesize that the great reduction in alcohol intake during the last two weeks of the paradigm may depend on metabolic modifications which affect alcohol reinforcing properties. It seems therefore, that in our experimental conditions AFA-rats are able to control their drinking behaviour [45].

In this study, a significant preference for $10 \%$ ethanol solution was observed with respect to white wine in the first and in the second week of voluntary self-administration, while in the third and fourth week, AFA-rats drank almost the same small amounts of the two beverages. The curve for ethanol solution intake mirrored the alcohol drinking pattern described above, since peaks and drops in drinking behaviour depended on ethanol consumption. As far as white wine concerns, AFA-rats displayed a low preference for this beverage during the whole 3-bottle choice paradigm. This result was unexpected, since rodents are preferentially oriented to consume sweeteners containing ethanol solutions, which increase self-administration, and less willingly to consume ethanol in water vehicle when other fluids are available $[46,47]$. Our data suggest that alcohol acceptance behaviour in the rat is not influenced by the same organolectic properties that are instead so relevant for humans. In our study, indeed, rats did not like wine, since they enjoyed alcohol properties choosing ethanol rather than white wine.

Some studies in the rat addressed the issue of the relationship between alcohol preference and stress/anxiety. For doses able to produce intoxication alcohol may induce the body's stress response [48]. On the other hand acute exposure to low doses of alcohol may reduce the response to stressors in animals and humans. Our data show that AFA-animals did not tend to increase their alcohol intake during the fourth week of the free-choice paradigm, under stressful conditions, like swimming in the Morris water maze, as could be expected according to the "tension reduction hypothesis of alcohol consumption" [49]. However, our observations are consistent with other reports showing that low doses of alcohol were able to reduce anxiety-like behaviour in rats subjected to strenuous activity in a running wheel and improved human performance of a complex mental problem-solving task under stressful conditions [50]. It seems therefore, that AFA-rats regulated their alcohol intake on the basis of some internal homeostatic mechanisms which allowed them to arrange an adaptive 
coping strategy to the stressful context represented by the Morris water maze.

AFA-rats were then tested in the open-field to assess whether the amounts of alcohol ingested could affect behavioural reactivity: a significant increase in locomotor activity and in explorative behaviour in the central areas of the arena were recorded, with respect to controls. Several data exist on the effects of acute ethanol on locomotor activity showing that it is strictly dependent on doses and modalities of administration, and on time of measurement, as well as on strain and species [51,52]. In most studies, ethanolinduced locomotion has been reported in ethanol preferring rats [53,54], and following an acute administration [55]. The present findings are in accordance with other reports showing that moderate doses of ethanol stimulate motor activity in rodents [56,57]. The stimulatory activity of chronic ethanol on ambulation was interpreted on the basis of a reduced level of anxiety [58], an effect that was repeatedly described for ethanol by using anxietylike and defensive behavioural tests [29]. Indeed, the open-field arena is generally considered to be a stressful, fear-arousing context, aimed to the evaluation of the spontaneous exploration of the environment [59-63]. More anxious, emotional animals tend to ambulate less and stay away from the central squares of the arena. On the contrary, a reduction in the emotional state is correlated to an increased behavioural reactivity in the open-field environment $[62,64]$. In this study, alcohol self-administration increased all the parameters measured in this test: the increase in the amount of time spent in the centre and in central locomotion in the openfield would favour an interpretation in terms of alcohol-induced behavioural activation and anxiolytic effects. It is also assumed that locomotor activity in such inescapable arena reflects the rewarding component of novelty [65]. Thus, the increase in behavioural reactivity observed in the open-field might reflect the positive reinforcing or euphorigenic properties of ethanol, since both phenomena result from activation of common neural pathways $[66,67]$.

When the animals were tested in the MWM in order to assess the acquisition of spatial learning and memory tasks, a different behavioural pattern was observed, according to the phases of the task. In particular, both groups were capable of acquiring a place learning with multiple trials, suggesting that AFA did not affect place learning. This result, though in contrast with previous findings of impaired memory acquisition in spatial tasks after chronic alcohol consumption [68], is consistent with reports showing that in general alcohol does not affect the processing of spatial information [41]. Interestingly in our study AFA-rats displayed a better performance in the new place learning of the reversal than controls. In this session, the initial position of the platform was moved to the opposite quadrant, and rats were required to process inner [69] and outer spatial information in order to find the new platform location. AFA-rats spent less than half the time necessary for the controls to find the platform in the first trial of the first day of the reversal, and shorter latencies were also recorded in the second and third trial. Alcohol was able to induce a facilitatory effect just in a task that requires a new processing of spatial information. It is here suggested that AFA, in amounts, modalities and time showed in this study, enhanced spatial flexibility, when an unexpected change in the environment (new platform location) called for an adaptive response to get a solution. While control rats appeared to be linked to the memory of the former platform position, as shown by the large amount of time spent in the former SE quadrant, AFA-rats did not give such relevance to those memory traces, but set up a new and successful strategy of searching to overcome the unexpected difficulty of the task.

However, in the second and third day of the reversal, both groups showed the same level of performance as proved by the almost overlapping escape latency curves that mirror the efficiency of the spatial cognitive functions. AFA did not affect therefore, reference memory processes.

The adaptive responses to environmental challenges involve both cognitive and emotional functions. Emotionality, in particular, can play a relevant role in promoting, or in impairing, some cognitive functions helpful for adaptation, such as spatial orientation skills and cognitive flexibility, both necessary for problem solving. In our study, moderate alcohol intake reduced emotionality and facilitated the adaptive responses and problem solving, enhancing behavioural flexibility and spatial orientation processing. Moreover, our data show that, the persistence of previous mnestic traces when an environmental change occurs, not always mirrors a successful adaptive strategy. A particularly intriguing feature was the rat ability to self-regulate its alcohol intake in the last two weeks of the AFA paradigm employed in this study. This evidence urges to check on those processes that in same individuals conversely, lead to the failure of self-controlled alcohol consumption, as well as additional work is required to identify mechanisms responsible for the cognitive facilitation exerted by moderate alcohol self-administration. Our results, far from promoting alcohol as a cognitive enhancer, suggest to encourage appropriate drinking advices and information campaigns which emphasize that drinking is not bad in itself - it is how much and how often it is consumed.

\section{Acknowledgements}

The authors would like to thank Dr. Gaetano Leto, and Prof. Antonio Bartolotta for their excellent statistical support, and Ignazio Barberi and Dario Licata for their relevant technical help.

\section{References}

[1] Porrino LJ, Williams-Hemby L, Whitlow C, Bowen C, Samson HH. Metabolic mapping of the effects of oral alcohol self-administration in rats. Alcohol Clin Exp Res 1998;22(1).

[2] Koob GF, Rassnick S, Heinrichs S, Weiss F. Alcohol, the reward system and dependence. In: Jansson B, Jornvall H, Rydberg U, Terenius L, Vallee BL, editors. Experientia supplementum, toward a molecular basis of alcohol use and abuse, vol. 71. Basal: Birkhauser-Verlag; 1994. p. 103-14.

[3] Koob GF, Roberts AJ, Schulteis G, Parsons LH, Heyser CJ, Hyytia P, et al. Neurocircuitry targets in ethanol reward and dependence. Alcohol Clin Exp Res $1998 ; 22$.

[4] Wikler A. A psychodynamic study of a patient during experimental selfregulated re-addiction to morphine. Psychiatr Q 1952;26:270-93.

[5] Koob GF, Volkow ND. Neurocircuitry of addiction. Neuropsychopharmacology 2010;35:217-38.

[6] Dudley R. Fermenting fruit and the historical ecology of ethanol ingestion: Is alcoholism in modern humans an evolutionary hangover? Addiction 2002;97:381-8.

[7] Spanagel R. Recent animal models of alcoholism. Alcohol Res Health 2000;24(2).

[8] Spanagel R. Alcohol addiction research: from animal models to clinics. Best Pract Res Clin Gastroenterol 2003;17:507-18.

[9] Wiens F, Zitzmann A, Lachance MA, Yegles M, Prags F, Wurst FM, et al. Chronic intake of fermented floral nectar by wild treeshews. PNAS 2008;105:10426-31.

[10] Bell SM, Gosnell BA, Krahn DD, Meisch RA. Ethanol reinforcement and its relationship to saccharin preference in Wistar rats. Alcohol 1994;11:141-5.

[11] Parsons OA, Nixon SJ. Cognitive functioning in sober social drinkers: a review of the research since 1986. J Stud Alcohol 1998;59:180-90.

[12] Sullivan EV, Pfefferbaum A. Neurocircuitry in alcoholism: a substrate of disruption and repair. Psychopharmacology (Berl) 2005;180:583-94.

[13] Yonker JE, Nilson LG, Herlitz A, Anthenelli RM. Sex differences in spatial visualization and episodic memory as a function of alcohol consumption. Alcohol Alcohol 2005;40:201-7.

[14] Tzambazis K, Stough C. Alcohol impairs speed of information processing and simple choice reaction time and differentially impairs higher-order cognitive abilities. Alcohol Alcohol 2000;35:197-201.

[15] Dom G, De Wilde B, Hulstijn W, Van den Brink W, Sabbe B. Decision-making deficits in alcohol-dependent patients with and without comorbid personality disorder. Alcohol Clin Exp Res 2006;30:1670-7.

[16] Prat $G$, Adan $A$, Pérez-Pàmies $M$, Sànchez-Turet $M$. Neurocognitive effects of alcohol hangover. Addict Behav 2008;33:15-23.

[17] Reynolds K, Lewis LB, Nolen JDL, Kinney GL, Sathya B, He J, et al. Alcohol consumption and risk of stroke: a meta-analysis. JAMA 2003;289:579-88.

[18] Mukamal KJ. Alcohol use and prognosis in patients with coronary heart disease. Prev Cardiol 2003;6:93-8. 
[19] Homma S. Moderate alcohol consumption is associated with better endothelial function: a cross sectional study. BMC Cardiovasc Disord 2009;9:8.

[20] Suzuki K, Elkind MSV, Boden-Albala B, Jin Z, Berry G, Di Tullio MR, et al. Moderate alcohol consumption is associated with better endothelial function: a cross sectional study. BMC Cardiovasc Disord 2009;9, art. 8.

[21] Anttila T, Helkala EL, Viitanen M, Kåreholt I, Fratiglioni L, Winblad B, et al. Alcohol drinking in middle age and subsequent risk of mild cognitive impairment and dementia in old age: a prospective population based study. Br Med J 2004;329:539-42.

[22] Rossetti ZL, Carboni S, Stancampiano R, Sori P, Pepeu G, Fadda F, et al. Bidirectional modulation of spatial working memory by ethanol. Alcohol Clin Exp Res 2002;26:181-5.

[23] Mikolajczak P, Okulicz-Kozaryn I, Nowaczyk M, Kaminska E. Ethanol facilitation of short-term memory in adult rats with a disturbed circadian cycle. Alcohol Alcohol 2001;36:292-7.

[24] Pohorecky LA. Biphasic action of ethanol. Biobehav Rev 1977;1:231-40.

[25] Davidson D, Hutchisonb K, Dagona C, Swiftc R. Assessing the stimulant effects of alcohol in humans. Pharmacol Biochem Behav 2002;72:151-6.

[26] Agabio R, Carai MAM, Lobina C, Pani M, Reali R, Vacca G, et al. Alcohol stimulates motor activity in selectively bred Sardinian alcohol preferring (sP), but not in Sardinian alcohol-nonpreferring (sNP) rats. Alcohol 2001;23:123-6.

[27] Rodd Z, Bell R, McKinzie D, Webster A, Murphy J, Lumeng L, et al. Low-dose stimulatory effects of ethanol during adolescence in rat lines selectively bred for high alcohol intake. Alcohol Clin Exp Res 2004;28:535-43.

[28] Stewart RB, Gatto GJ, Lumeng L, Li TK, Murphy JM. Comparison of alcoholpreferring (P) and nonpreferring (NP) rats on tests of anxiety and for the anxiolytic effects of ethanol. Alcohol 1993;10:1-10.

[29] Spanagel R, Montkowski A, Allingham K, Shoaib M, Holsboer F, Landgraf R, et al. Anxiety: a potential predictor of vulnerability to the initiation of ethanol self-administration in rats. Psychopharmacology (Berl) 1995;122:369-73.

[30] Moeller C, Wiklund L, Sommer W, Thorsell A, Heilig M. Decreased experimental anxiety and voluntary ethanol consumption in rats following central but not basolateral amygdala lesions. Brain Res 1997;760:94-101.

[31] Da Silva GE, Vendruscolo LF, Takahashi RN. Effects of ethanol on locomotor and anxiety-like behaviours and the acquisition of ethanol intake in Lewis and spontaneously hypertensive rats. Life Sci 2005;77:693-706.

[32] Henniger MSH, Spanagel R, Wigger A, Landgraf R, Hölter SM. Alcohol selfadministration in two rat lines selectively bred for extremes in anxiety-related behaviour. Neuropsychopharmacology 2002;26:729-36.

[33] Fernandez-Teruel A, Driscoll P, Gil L, Aguilar R, Tobea A, Escorihuela RM, et al. Enduring effects of environmental enrichment on novelty seeking, saccharin and ethanol intake in two rat lines (RHA/Verh and RLA/Verh) differing in incentive-seeking behavior. Pharmacol Biochem Behav 2002;73:225-31.

[34] Harkany T, Sasvari M, Nyakas C. Chronic ethanol ingestion-induced changes in open-field behavior and oxidative stress in the rat. Pharmacol Biochem Behav 1997:58:195-201.

[35] Beracochea DJ, Lescaudron L, Verna A, Jaffard R. Neuroanatomical effects of chronic ethanol consumption on dorsomedial and anterior thalamic nuclei and on substantia innominata in mice. Neurosci Lett 1987:73:81-4.

[36] Beracochea DJ, Tako AN, Jaffard R. Accelerated rates of forgetting of spatial information during aging and long-term ethanol consumption in mice: evidence for two distinct forms of amnesia. Psychobiology 1989;17:358-62.

[37] Beracochea DJ, Micheau J, Jaffard R. Memory deficits following chronic alcohol consumption in mice: relationships with hippocampal and cortical cholinergic activities. Pharmacol Biochem Behav 1992;42:749-53.

[38] Melis F, Stancampiano R, Imperato A, Carta G, Fadda F. Chronic ethanol consumption in rats: correlation between memory performance and hippocampal acetylcholine release in vivo. Neuroscience 1996;74:155-9.

[39] Steigerwald ES, Miller MW. Performance by adult rats in sensory-mediated radial arm maze tasks is not impaired and may be transiently enhanced by chronic exposure to ethanol. Alcohol Clin Exp Res 1997;21:1553-9.

[40] Kalev-Zylinska ML, During MJ. Paradoxical facilitatory effect of low-dose alcohol consumption on memory mediated by NMDA receptors. J Neurosci 2007;27(39):10456-67.

[41] Santín LJ, Rubio S, Begega A, Arias JL. Effects of chronic alcohol consumption on spatial reference and working memory tasks. Alcohol 2000;20:149-59.

[42] Siegmund S, Vengeliene V, Singer MV, Spanagel R. Influence of age at drinking onset on long-term ethanol self-administration with deprivation and stress phases. Alcohol Clin Exp Res 2005;29:1139-45.

[43] Spanagel R, Hölter SM. Long-term alcohol self-administration with repeated alcohol deprivation phases: an animal model of alcoholism? Alcohol Alcohol 1999;34:231-43.
[44] Eckhardt MJ, File SE, Gessa GL, Grant KA, Guerri C, Hoffman PL, et al. Effects of moderate alcohol consumption on the central nervous system. Alcohol Clin Exp Res 1998;22:998-1040.

[45] Spanagel R. Alcoholism: a systems approach from molecular physiology to addictive behaviour. Physiol Rev 2009;89:649-705

[46] Samson HH. Initiation of ethanol reinforcement using a sucrose-substitution procedure in food- and water-sated rats. Alcohol Clin Exp Res 1986;10:436-42.

[47] Schwarz-Stevens K, Samson HH, Tolliver L, Lumeng L, Li TK. The effects of ethanol initiation procedures on ethanol reinforced behavior in the alcoholpreferring rat. Alcohol Clin Exp Res 1991;15:277-85.

[48] Waltman C, Blevins Jr LS, Boyd G, Wand GS. The effects of mild ethanol intoxication on the hypothalamic-pituitary-adrenal axis in non-alcoholic men. J Clin Endocrinol Metab 1993;77:518-22.

[49] Conger JJ. Alcoholism: theory, problem and challenge II. Reinforcement theory and the dynamics of alcoholism. QJ Stud Alcohol 1956;13:296-305.

[50] Kalant H. Stress-related effects of ethanol in mammals. Crit Rev Biotechno 1990;9:265-72.

[51] Krimmer EC, Schechter MD. HAD and LAD rats respond differently to stimulating effect but not discriminative effects of ethanol. Alcohol 1991;9:71-4.

[52] Quintanilla ME. Effect of low doses of ethanol on spontaneous locomotor activity in UChB and UChA rats. Addict Biol 1999;4:443-8.

[53] Paivarinta P, Korpi ER. Voluntary ethanol drinking increases locomotor activity in alcohol-preferring AA rats. Pharmacol Biochem Behav 1993;44:127-32.

[54] Colombo G, Agabio R, Lobina C, Reali R, Vacca G, Gessa GL, et al. Stimulation of locomotor activity by voluntarily consumed ethanol in Sardinian alcoholpreferring rats. Eur J Pharmacol 1998;357:109-13.

[55] Gingras MA, Cools AR. Analysis of the biphasic locomotor response to ethano in high and low responders to novelty: a study in Nijmegen Wistar rats. Psychopharmacology (Berl) 1996;125(3):258-64.

[56] Boerngen-Lacerda R, Souza-Formigoni MLO. Does the increase in locomotion induced by ethanol indicate its stimulant or anxiolytic properties? Pharmaco Biochem Behav 2000;67:225-32.

[57] Correa M, Arizzi MN, Betz A, Mingote S, Salamone JD. Locomotor stimulant effects of intraventricular injections of low doses of ethanol in rats: acute and repeated administration. Psychopharmacology (Berl) 2003;170:368-75.

[58] Alvarez C, Prunell M, Boada J. Effect of naloxone on behavioral changes induced by subchronic administration of ethanol in rats. Pharmacol Biochem Behav 1998;59:961-5.

[59] Cannizzaro C, Martire M, Cannizzaro E, Provenzano G, Gagliano M, Carollo A et al. Long-lasting handling affects behavioural reactivity in adult rats of both sexes prenatally exposed to diazepam. Brain Res 2001;904:225-33.

[60] Cannizzaro C, Plescia F, Martire M, Gagliano M, Cannizzaro G, Mantia G, et al. Single, intense prenatal stress decreases emotionality and enhances learning performance in the adolescent rat offspring: Interaction with a brief, daily maternal separation. Behav Brain Res 2006;169:128-213.

[61] Prut L, Belzung C. The open field as a paradigm to measure the effects of drugs on anxiety-like behaviours: a review. Eur J Pharmacol 2003;463:3-33.

[62] Kelley AE. Locomotor activity and exploration. In: Saghal A, editor. Behavioural neuroscience. A practical approach, vol. 2. Oxford: Oxford Press; 1993. p. 1-21.

[63] Vallée M, Mayo W, Dellu F, Le Moal M, Simon H, Maccari S, et al. Prenatal stress induces high anxiety and postnatal handling induces low anxiety in adult offspring: correlation with stress-induces corticosterone injection. J Neurosc 1997; 17:2626-36.

[64] Cannizzaro C, Plescia F, Gagliano M, Cannizzaro G, Mantia G, La Barbera M, et al Perinatal exposure to 5-metoxytryptamine, behavioural-stress reactivity and functional response of 5-HT1A receptors in the adolescent rat. Behav Brain Res 2008;186:98-106.

[65] Bardo MT, Donohew RL, Harrington NG. Psychobiology of novelty seeking and drug seeking behaviour. Behav Brain Res 1996;77:23-43.

[66] Gessa GL, Muntoni F, Collu M. Low doses of ethanol activate dopaminergic neurons in the ventral tegmental area. Brain Res 1985;348:201-3.

[67] Boehm II, Moore SL, Walsh EM, Gross CD, Cavelli C, Gigante EA, et al. Linsenbardt DN using drinking in the dark to model prenatal binge-like exposure to ethanol in C57BL/6J mice. Dev Psychobiol 2008;50:566-78.

[68] Arendt T, Allen Y, Marchbanks RM, Schugens MM, Sinden J, Lantos PL, et al. Cholinergic system and memory in the rat: effects of chronic ethanol, embryonic basal forebrain brain transplants and excitotoxic lesions of cholinergic basal forebrain projection system. Neuroscience 1989;33:435-62.

[69] Rubio S, Begega A, Santin LJ, Arias JL. Improvement of spatial memory by (R)- $\alpha$ methylhistamine, a histamine H3-receptor agonist, on the Morris water-maze in rat. Behav Brain Res 2002;129(1-2):77-82. 